\title{
Percutaneous-endoscopic rendezvous via cap-assisted adult colonoscope to deal with biliary and multiple intestine strictures after total gastrectomy
}

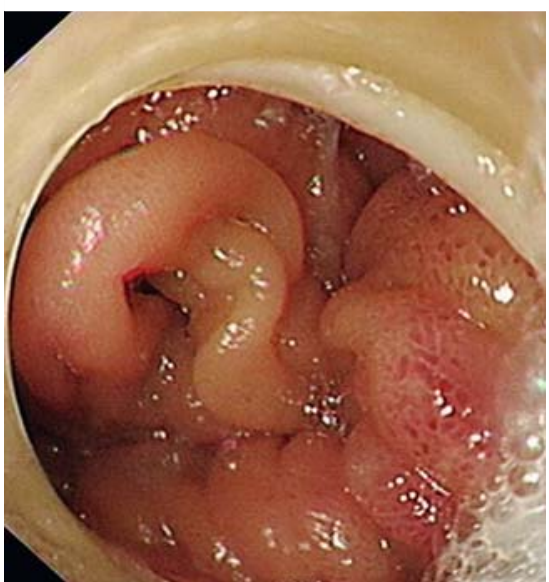

- Fig. 1 Jejunal stricture, causing vomiting, near the esophagojejunostomy.

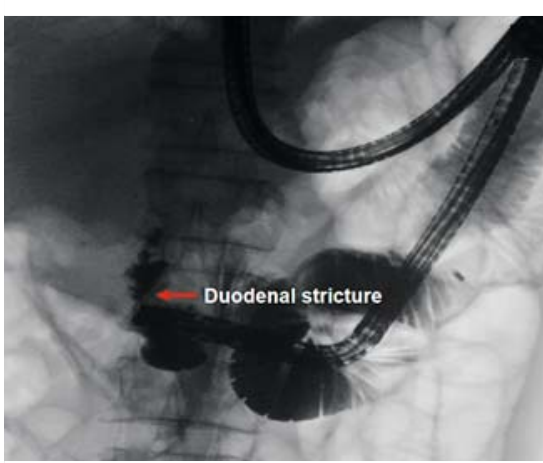

Fig. 2 The papilla could not be reached by the cap-assisted adult colonoscope because of the duodenal stricture, which was confirmed after injection of contrast agent.

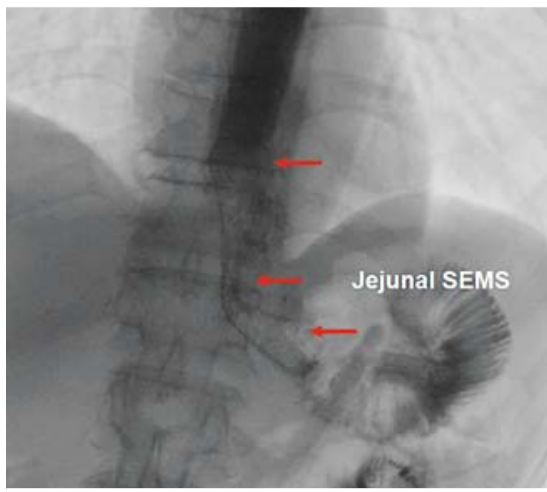

Fig. 3 An intestinal metal stent, $22 \mathrm{~mm}$ in diameter and $8 \mathrm{~cm}$ in length, was placed across the jejunal stricture.

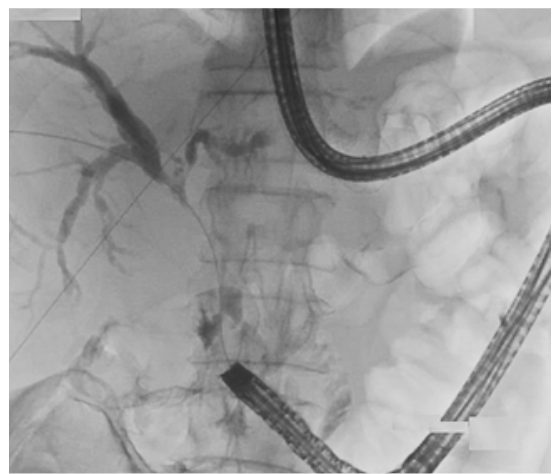

- Fig. 4 Cholangiography indicated significant stricture of the common bile duct.

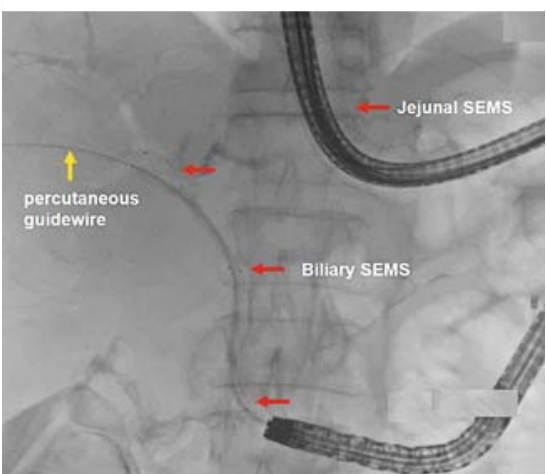

Fig. 5 A metal stent, $8 \mathrm{~mm}$ in diameter and $10 \mathrm{~cm}$ in length was endoscopically inserted into the bile duct across the biliary and duodenal stricture.
A 68-year-old man was admitted with vomiting and jaundice. He had undergone total gastrectomy and Roux-en-Y jejunojejunostomy for cardiac cancer a year earlier. Magnetic resonance imaging indicated abdominal tumor metastasis and dilatation of the intrahepatic bile ducts.

A cap-assisted adult colonoscope was used for endoscopic biliary drainage owing to abnormal anatomy. A jejunal stenosis was found near the esophago- jejunostomy and a 1.5-cm-diameter balloon was applied to dilate the stricture ( $\vee$ Fig. 1). The colonoscope then passed through the stenosis into the duodenum. However, the papilla could not be reached because of the duodenal stricture and cannulation was not performed (> Fig.2). Vomiting was not relieved after endoscopic dilation and a 22-mm-diameter uncovered metal stent was inserted ( Fig.3). After 2 days, a guidewire was percutaneously inserted into the intra- 
hepatic bile duct and on to the intestine through the papilla under $\mathrm{X}$-ray guidance. The cap-assisted adult colonoscope entered the afferent limb and the guidewire was grasped by a biopsy forceps and pulled out through the endoscopy channel. Cholangiography indicated significant stricture of the common bile duct ( Fig.4). A self-expandable metal stent, $8 \mathrm{~mm}$ in diameter and $10 \mathrm{~cm}$ in length was endoscopically inserted into the bile duct across the biliary and duodenal stricture, which also allowed further endoscopic interventions when needed ( Fig.5). A nasobiliary tube was placed within the bile duct for better biliary drainage and the guidewire was then removed ( $\triangleright$ Video 1 ). The patient's symptoms resolved and he was discharged after 1 week.

Balloon-assisted enteroscopy is commonly applied for endoscopic retrograde cholangiopancreatography (ERCP) in patients with total gastrectomy and Rouxen-Y jejunojejunostomy [1]. However, special instruments and small-caliber endoscope channel limit its application [2]. In this novel approach, we applied an adult colonoscope with cap to perform ERCP, and percutaneous rendezvous was useful when the papilla could not be reached.

Endoscopy_UCTN_Code_TTT_1AP_2AD
Competing interests

The authors declare that they have no conflict of interest.

\section{The authors}

Zhenghong Li, Weiming Dai, Lijuan Yang, Rong Wan, Xiaobo Cai

Department of Gastroenterology, Shanghai General Hospital, Shanghai Jiaotong University, School of Medicine, Shanghai, China

\section{Corresponding author}

\section{Xiaobo Cai, MD}

Department of Gastroenterology, Shanghai General Hospital, School of Medicine,

Shanghai Jiaotong University, Haining Road

100, Shanghai 200080, China

Fax: +86-21-63240090

caixiaobo1979@hotmail.com

\section{References}

[1] Li K, Huang YH, Yao W et al. Adult colonoscopy or single-balloon enteroscopy-assisted ERCP in long-limb surgical bypass patients. Clin Res Hepatol Gastroenterol 2014; 38: 513-519

[2] Lopes TL, Baron TH. Endoscopic retrograde cholangiopancreatography in patients with Roux-en-Y anatomy. J Hepatobiliary Pancreat Sci 2011; 18: 332-338
Bibliography

Endoscopy 2021; 53: E380-E381

DOI 10.1055/a-1304-3304

ISSN 0013-726X

published online 3.12 .2020

(c) 2020. Thieme. All rights reserved.

Georg Thieme Verlag KG, Rüdigerstraße 14 70469 Stuttgart, Germany

\section{ENDOSCOPY E-VIDEOS}

https://eref.thieme.de/e-videos

回回 Endoscopy E-Videos is a free

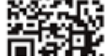
access online section, reporting on interesting cases and new

techniques in gastroenterological endoscopy. All papers include a high quality video and all contributions are freely accessible online.

This section has its own submission website at https://mc.manuscriptcentral.com/e-videos 